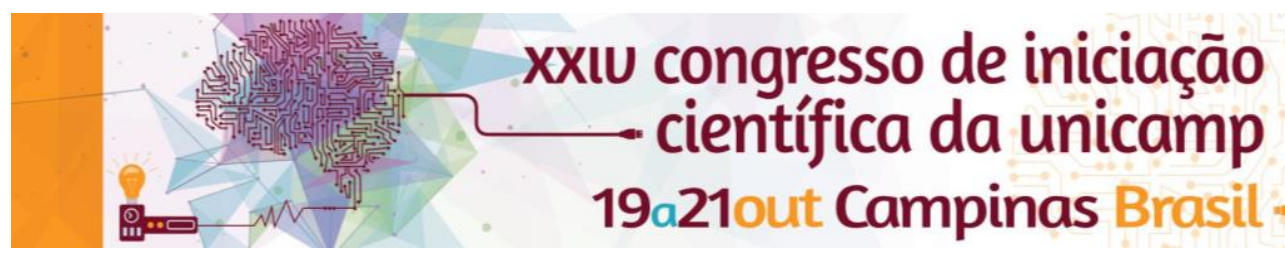

\title{
Manutenção de reservatórios de fluoreto no biofilme dental após tratamentos com diferentes concentrações de cálcio e flúor.
}

\section{Larissa M. Alves*, Diego F. Nóbrega, Tarcisio J. Oliveira, Altair A. Del Bel Cury, Livia M. A. Tenuta, Jaime Cury}

\section{Resumo}

Nos últimos anos, terapias mais efetivas para o controle de cárie, que potencializam o efeito do fluoreto, têm sido estudadas. Uma delas sugere a combinação de tratamentos com cálcio (Ca), previamente ao uso de fluoreto $(F)$, para aumentar a retenção deste no biofilme dental, na forma de fluoreto de cálcio. No entanto, não se conhece por qual período de tempo esse reservatório permanece no biofilme dental. Neste trabalho avaliamos a concentração de $\mathrm{Ca}$ e $\mathrm{F}$ em biofilmes teste tratados com concentrações crescentes de $\mathrm{Ca}$ (de 0 a $10 \mathrm{mM}$ ) e $\mathrm{F}$ (de 0 a 225 ppm F), e expostos a cavidade bucal por 30 ou 75 min, num teste in situ de cariogenicidade. As concentrações de $\mathrm{Ca}$ e $\mathrm{F}$ foram determinadas após extração ácida do biofilme, utilizando dosagem colorimétrica e eletrodo íon-específico, respectivamente. Até o momento, apenas as análises de Ca foram realizadas e serão apresentadas.

\section{Palavras-chave}

Cálcio, flúor e biofilme.

\section{Introdução}

É consenso que o fluoreto interfere na progressão das lesões de cárie quando disponível nos fluidos bucais (Cury e Tenuta, 2008). Assim, terapias para potencializar esse efeito estão sendo estudadas, como o tratamento de cálcio previamente ao uso do fluoreto, para aumentar a retenção deste no biofilme, na forma de fluoreto de cálcio ( $\left.\mathrm{CaF}_{2}\right)$ (Vogel et al, 2008). No entanto, não se conhece o período que esse reservatório permanece no biofilme. O objetivo deste trabalho foi analisar as concentrações de $\mathrm{Ca}$ e $\mathrm{F}$ em amostras de biofilme (placa teste) tratadas com Ca e F, antes e após a utilização in situ.

\section{Resultados e Discussão}

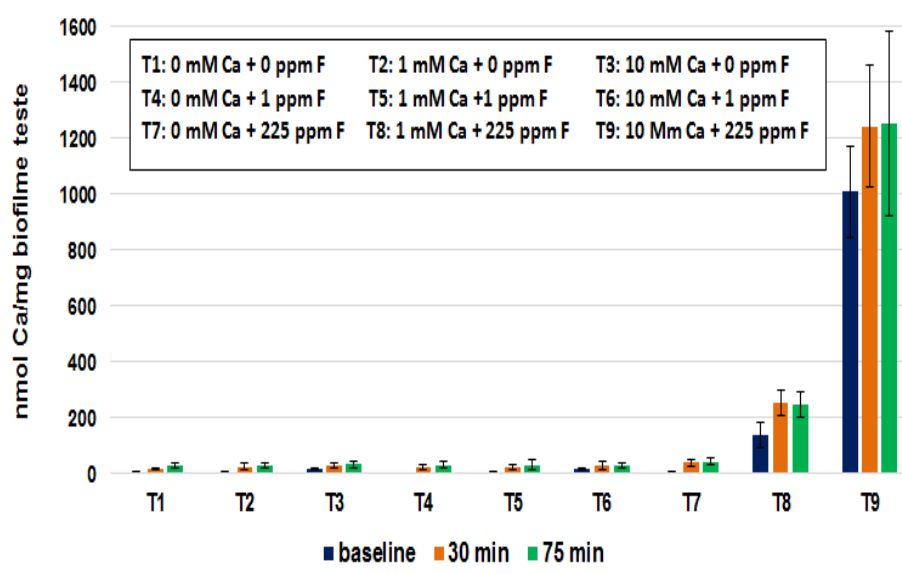

Figura 1. Concentração de $\mathrm{Ca}$ no biofilme teste imediatamente após os tratamentos (baseline) ou após ser exposto na cavidade bucal por 30 ou 75 min, em um modelo in situ para avaliação de cárie.
A concentração de $\mathrm{Ca}$ observada no biofilme teste foi função da concentração do tratamento $(0,1$ e $10 \mathrm{mM})$, porém para os grupos 8 e 9 , nos quais ocorre a formação do mineral fluoreto de cálcio, foram em muito aumentadas. Após exposição na cavidade bucal, um aumento nessas concentrações foi observado, possivelmente pela incorporação de $\mathrm{Ca}$ presente nos fluidos bucais (saliva e fluido do biofilme). Portanto, os reservatórios de fluoreto de cálcio no biofilme não são eliminados rapidamente, devendo permanecer por longos períodos de tempo.

\section{Conclusões}

Os resultados sugerem que os reservatórios de fluoreto de cálcio formados no biofilme não são rapidamente perdidos, podendo funcionar como um reservatório de liberação lenta do íon.

\section{Agradecimentos}

Ao $\mathrm{PIBIC/CNPq} \mathrm{e} \mathrm{ao} \mathrm{CNPq} \mathrm{pelas} \mathrm{bolsas} \mathrm{concedidas} \mathrm{aos}$ primeiro e segundo autores, respectivamente, e aos voluntários que participaram dessa pesquisa.

${ }^{1}$ Cury JA, Tenuta LM. How to maintain a cariostatic fluoride concentration in the oral environment. Adv Dent Res 2008; 20:13-6.

${ }^{2}$ Vogel GL, Schumacher GE, Chow LC, Takagi S, Carey CM. Ca pre-rinse greatly increases plaque and plaque fluid F. J Dent Res. 2008 May;87(5):466-9. 